\title{
Mechanical, Thermal and Interfacial Properties of Jute Fabric-Reinforced Polypropylene Composites: Effect of Potassium Dichromate
}

\author{
Jahangir A. Khan ${ }^{1,2}$, Mubarak A. Khan ${ }^{1 *}$, Rabiul Islam², Abdul Gafur ${ }^{3}$ \\ ${ }^{1}$ Radiation and Polymer Chemistry Laboratory, Institute of Nuclear Science and Technology, Bangladesh Atomic Energy Commis- \\ sion, Dhaka, Bangladesh. ${ }^{2}$ Department of Chemistry, Jahangirnagar University, Dhaka, Bangladesh. ${ }^{3}$ PP \&PDC, Bangladesh Council \\ of Scientific and Industrial Research, Dhaka, Bangladesh. \\ E-mail: makhan.inst@gmail.com,mjakhan_edu@yahoo.com
}

Received September $2^{\text {nd }}, 2010$; revised September $23^{\text {rd }}, 2010$; accepted October $6^{\text {th }}, 2010$.

\begin{abstract}
Composites based on jute fabrics and polypropylene was fabricated by heat-press molding technique. The mechanical properties of the composites such as tensile strength, tensile modulus, bending strength, bending modulus and impact strength were measured in dependence of fiber contents. In order to improve fiber-matrix interaction, jute fabrics were treated with aqueous solutions of $\mathrm{K}_{2} \mathrm{Cr}_{2} \mathrm{O}_{7}(0.005-0.05 \% \mathrm{w} / \mathrm{v})$. Composite prepared with $0.02 \% \mathrm{~K}_{2} \mathrm{Cr}_{2} \mathrm{O}_{7}$ treated jute fabrics showed the highest values of the mechanical properties. Thermogravimetric (TG/DTG) data of PP, jute fabrics and composites showed that thermal degradation temperatures of composites shifted to higher temperature regions compared to PP or jute fabrics. Treatment of jute fabrics improved the thermal stability of the composite considerably. Scanning electron microscopic images of tensile fractured sides of untreated and treated composites illustrated that better fiber-matrix interfacial interaction occurred in treated composite. The relative tendency of water absorption of both untreated and treated composites was also explored.
\end{abstract}

Keywords: Composites, Jute fabric, Polypropylene, Mechanical properties, Thermal properties

\section{Introduction}

Environment-friendly and cost effective composites have recently been received considerable attention among the scientists. The use of man-made fibers (such as, glass, carbon) as reinforcements in composites is now critically considered due to environmental concern though they have possessed excellent mechanical and thermal properties, and durability. These properties make difficult to carry out suitable disposal processing. For example, incineration of discarding glass fiber based composite generates a lot of black smoke and bad odors and often creates damage to incinerator by fusion of glass fibers. Reclamation processing generates also a large environmental load; since synthetic fibers are not decomposed easily. To avert this problem, the use of natural fibers based composites is increasing continuously. Natural fibers have some advantages over man-made fibers in that they are cheap, highly available and renewable, with low density and high specific properties as well as they are biodegradable and less abrasive [1]. Natural fibers such as jute, ramie, hemp, sisal, bamboo, banana, oil palm fibers and so on are used as reinforcements in polymer matrix composites. Among these fibers, jute is of particular interest because, jute grows plenty in Bangladesh and Eastern part of India and composites made of jute fibers have moderate tensile and flexural properties compared with other natural fibers. Being hydrophilic in nature, like other natural fibers, jute fiber possesses poor adhesion with hydrophobic polymer matrix [2]. So, pretreatment of natural fibers or polymer matrices or both is necessary for better fiber-matrix interface adhesion. Many researchers are working on jute fibers based composites to make better compatibility between fibers and polymer matrices. Khan et al. [3] used silane and acrylic monomers to improve the mechanical properties of juteBiopol composite. Delignification (bleaching) brought better adhesion between fiber and polymer matrix [4]. Joseph and co-workers [5-6] observed that permanganate treated sisal fiber reinforced low density polyethylene (LDPE) composites showed an enhancement in tensile 
properties due to the permanganate induced grafting. Researchers [7-9] worked on jute fibers/polyolefin composites and reported improved properties of the composites. Different chemical modifications including permanganate treatment on natural fibers for use in natural fiber reinforced composites were reviewed by Xue Li et al. [10] and they reported that mechanical properties of the composites improved significantly. Oxidation of cellulose with potassium dichromate-sulfuric acid, potassium dichromate-oxalic acid, potassium permanganate, sodium hypochlorite and periodate were performed by different researchers [11-13].

The major constituent of jute fiber is cellulose which contains one primary alcohol group at C-6 position of the cellulose backbone and two secondary alcohol groups at $\mathrm{C}-2$ and C-3 positions. These alcohol groups are susceptible to the action of oxidizing agents. The oxycelluloses produced during oxidation of cellulose depend mainly on the types and strengths of the oxidizing agents used. The physical characteristics of cellulose materials also change during oxidation. For example, periodates and nitrogen dioxide oxidants attack crystalline as well as amorphous regions of the cellulose. On the other hand, common types of oxidizing agents (such as potassium dichromate, chromic acid, potassium permanganate etc.) mainly react into the amorphous portions and the surface of the crystallites. As a consequence of oxidizing effects, cellulose materials experience surface roughness and brittleness in fibers [14].

The present research work deals with the treatment of jute fabrics with aqueous potassium dichromate as oxidizing agent. Polypropylene is used as a matrix material. The prime objective of this work is to study the effect of potassium dichromate on the mechanical and thermal properties of the composites. The investigation also involves in characterizing the fiber-matrix interface by scanning electron microscope. The relative water absorption tendency of the untreated and treated composites has been studied.

\section{Experimental}

\subsection{Materials}

Jute fabrics (Hessian cloth) were supplied by SADAT Textile Industries Ltd., Dhaka, Bangladesh. Potassium dichromate $\left(\mathrm{K}_{2} \mathrm{Cr}_{2} \mathrm{O}_{7}\right)$ was received from Merck, Germany and Polypropylene (PP) pellets (trade name: Cosmoplene) from The Polyolefin Company (Singapore) Pte. Ltd. The materials were used as received.

\subsection{Surface Modification}

Jute fabrics were soaked in different concentrated solutions $(0.005$ to $0.05 \% \mathrm{w} / \mathrm{v})$ of aqueous $\mathrm{K}_{2} \mathrm{Cr}_{2} \mathrm{O}_{7}$ for $2 \mathrm{~min}$.
The soaked jute fabrics were intensively washed with running tap water to remove the unbound oxidizing agent. After soaking, jute fabrics were dried in an oven at $105^{\circ} \mathrm{C}$ for $6 \mathrm{hrs}$ and kept in a desiccator.

\subsection{Composites Fabrication}

PP sheets of desired size $(15 \mathrm{~cm} \times 13 \mathrm{~cm})$ were prepared by compressing PP pellets in the heat press (Carver, INC, USA, model 3856). For composite fabrication, sandwich was prepared using pre-weighed four layers jute fabrics and five layers PP sheets. The prepared sandwich was then compressed in the heat press at $190^{\circ} \mathrm{C}$ for $5 \mathrm{~min}$ under 5 tons pressure. After heat pressed, composites were cooled to another press (Carver: model 4128) operated at cooling mode.

\subsection{Mechanical Testing}

The tensile and bending tests of the composites were carried out by a universal testing machine (Hounsfield H50KS) according to DIN 53455 and DIN 53452 standard methods, respectively. Impact strength (Charpy) was carried out in an impact tester (MT-3016, Pendulum type, Germany) following ASTM D 6110- 97. All the results were taken as the average value of five samples.

\subsection{Thermal Analysis}

Thermogravimetric and differential thermal analyzer (TG/DTA 6300, USA) has been used to simultaneously perform thermo-gravimetric and differential thermal analytic measurement. The range of temperature was 30 to $600^{\circ} \mathrm{C}$. The system is run on a nitrogen environment. The gas is purged at $100 \mathrm{ml} / \mathrm{min}$. The rate of heating is maintained at $20^{\circ} \mathrm{C} / \mathrm{min}$.

\subsection{Scanning Electron Microscopy}

The non-conducting surface of the composites was coated with gold in agar auto sputter coater (model 108A, England) before subjected to Scanning Electron Microscope (SEM). The fiber matrix adhesion of the tensile fracture surface of the composites was examined by Scanning Electron Microscope (model XL 30, Philips, The Netherlands).

\subsection{Water Uptake}

Specimens of the composites (control and treated) were immersed in the static water glass beaker at room temperature for different time periods (up to 30 days). Before immersion, weight of the samples was taken. At certain time intervals, samples were taken out from the beaker and wiped smoothly with tissue paper and then weighed immediately. Percent of water uptake was then calculated using the following formula. 


$$
W_{u p}(\%)=\frac{W_{f}-W_{i}}{W_{i}} \times 100 \%
$$

Where,

$W_{u p}(\%)=$ percent water uptake of the sample

$W_{i}=$ weight of the sample before immersion in water

$W_{f}=$ weight of the sample after immersion in water

\section{Results and Discussion}

\subsection{Effect of Fiber Content on the Mechanical Properties of Composites}

The fiber volume fraction influences the mechanical properties of the composites. Tensile (TS) and bending (BS) strengths of the composites were measured as a function of jute content and the results are shown in Figure 1. Jute content in the composite varies from 28 to $52 \% \mathrm{w} / \mathrm{v}$. It is observed that TS and BS of the composites increase up to $45 \%$ jute content after that strengths of the composites decrease. The similar observation is also recorded for tensile modulus (TM) and bending modulus (BM) of the composites (Figure 2). The investigation reveals that $45 \%$ jute content performs the best of mechanical properties. The values of TS, BS, TM and BM were recorded as 52 $\mathrm{MPa}, 63 \mathrm{MPa}, 1.03 \mathrm{GPa}$ and $3.27 \mathrm{GPa}$ respectively. The highest values of mechanical properties exhibited by $45 \%$ fiber content composite may be explained in terms of orientation and homogeneity of fibers within the matrix. At this stage, fibers get maximum level of orientation and mixed homogeneously within the matrix. When load is applied, stress is uniformly distributed among the fibers. As a result, mechanical properties of the compo-

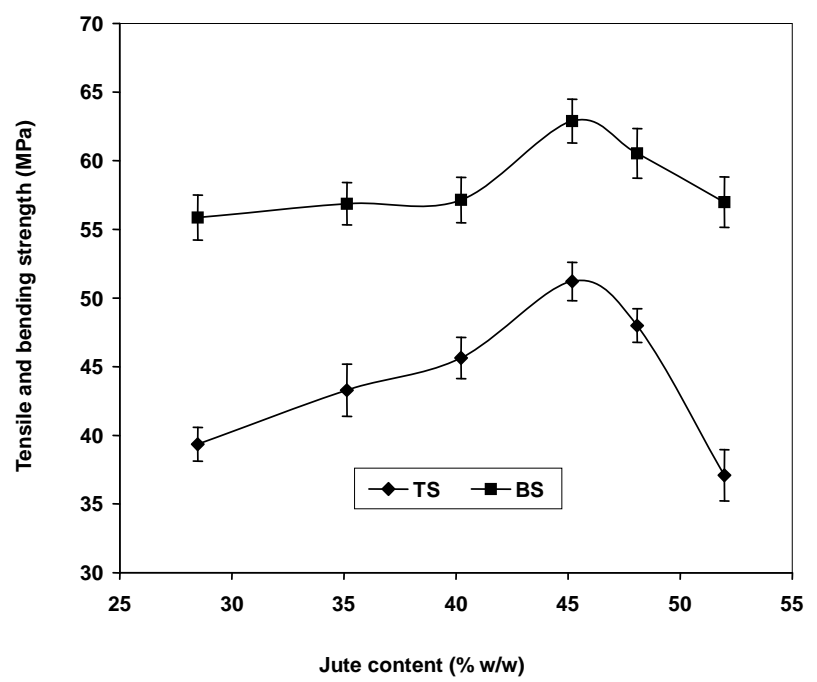

Figure 1. Effect of jute content on tensile and bending strength of the composite.

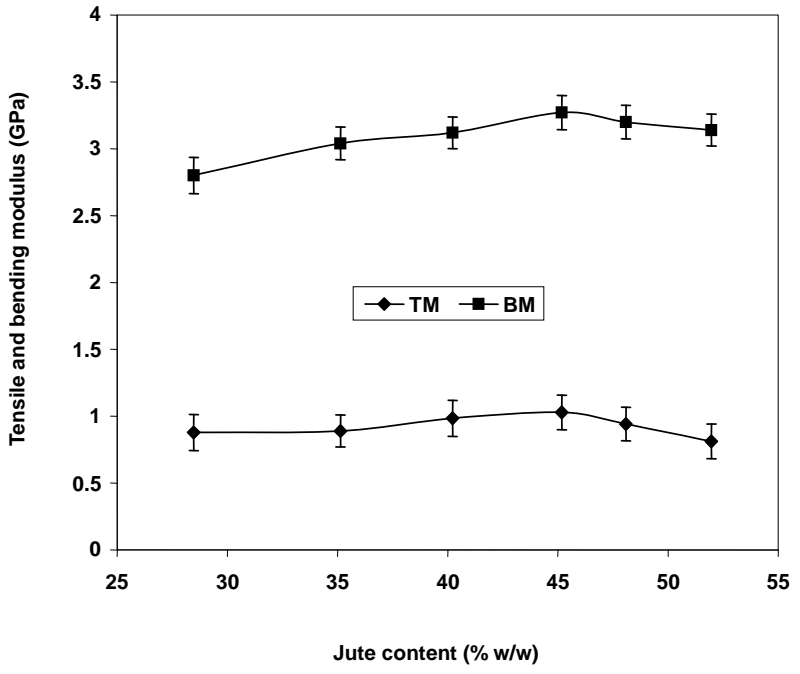

Figure 2. Effect of jute content on tensile and bending modulus of the composite.

sites achieve maximum values. At low fiber content, poor fiber population causes low load transfer capacity among the fibers. As a result, accumulation of stress occurs at certain points of the composite and strains are also found highly localized in the matrix [15]. This contributes poor mechanical properties of the composites at low fiber content. Where as, at high level of jute contents, fibers get agglomerated within the matrix which produces nonuniform stress transfer capacity. Also, too many fiber ends promote microcrack formation in the interface. As a result, strength and modulus of the composite again decrease $[15,16]$.

The effect of jute content on elongation at break $(\mathrm{Eb})$ of the composite is shown in Figure 3. It is found that $\mathrm{Eb}$

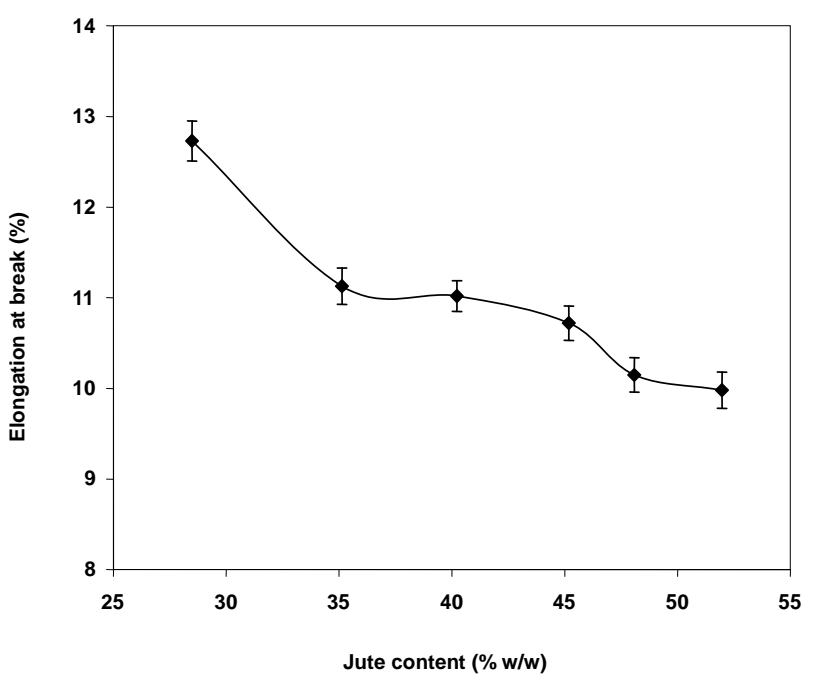

Figure 3. Effect of jute content on elongation at break of the composite. 
of the composite decreases as the jute content increases. At $28 \%$ jute content, $\mathrm{Eb}$ is $12.7 \%$ whereas at $52 \%$ jute content $\mathrm{Eb}$ is decreased to $9.9 \%$. It is generally believed that elongation decreases with the increase of modulus of the composites [17]. It is remarkable that, after $45 \%$ fiber content, the value of $\mathrm{Eb}$ further reduces with the decrease of modulus of the composite. It may be explained that jute fiber has much lower value of $\mathrm{Eb}$ than that of PP matrix and fiber volume fraction increases gradually after $45 \%$ jute content. Furthermore, the formation of microcracks at higher fiber content might have been responsible for the reduction of Eb. So, at first, up to optimum fiber content, modulus is likely to play the key role for the reduction of $\mathrm{Eb}$. Secondly, above the optimum level, decrease of $\mathrm{Eb}$ is mainly guided by the higher fiber content.

\subsection{Effect of $\mathrm{K}_{2} \mathrm{Cr}_{2} \mathrm{O}_{7}$ on the Mechanical Properties of Composites}

The effect of $\mathrm{K}_{2} \mathrm{Cr}_{2} \mathrm{O}_{7}$ on TS and BS of the composites is presented in Figure 4. It is observed that TS and BS increase up to $0.03 \% \mathrm{~K}_{2} \mathrm{Cr}_{2} \mathrm{O}_{7}$ treatment after that there is a decrease in strengths over the control sample. The similar behavior is also recorded for TM of the treated sample. On the other hand, treated composite had higher values of $\mathrm{BM}$ over the control sample for any concentration of the $\mathrm{K}_{2} \mathrm{Cr}_{2} \mathrm{O}_{7}$ solutions (Figure 5). It is also observed that all the mechanical parameters of the treated composite achieve the highest values for $0.02 \% \mathrm{~K}_{2} \mathrm{Cr}_{2} \mathrm{O}_{7}$ treatment over the other combinations. TS of the treated composite $\left(0.02 \% \mathrm{~K}_{2} \mathrm{Cr}_{2} \mathrm{O}_{7}\right.$ treated jute fabric) increases from 52 to $68 \mathrm{MPa}$ which is $30.8 \%$ increment from that of the control sample. BS increases from 63 to $77 \mathrm{MPa}$, which shows $22.2 \%$ enhancement. On the other hand,

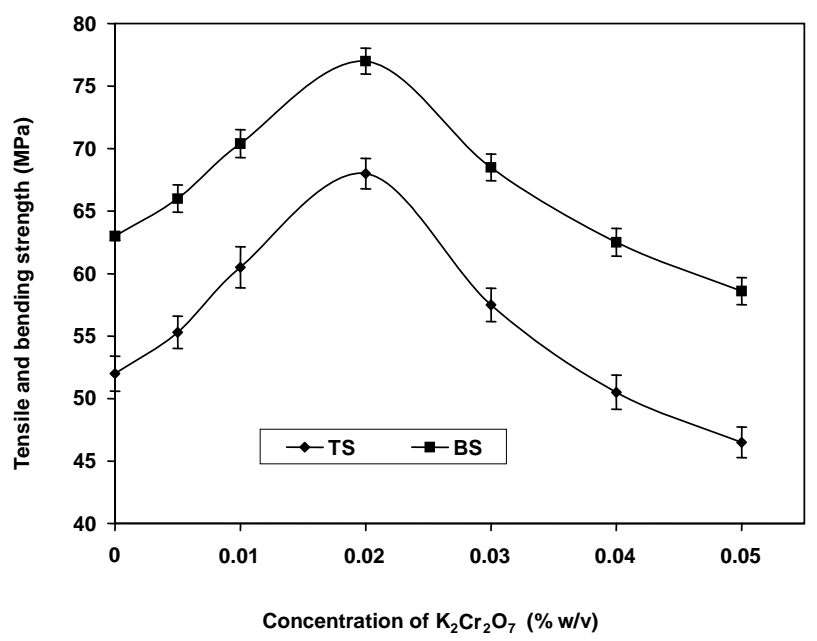

Figure 4. Effect of potassium dichromate on tensile and bending strength of the composite.

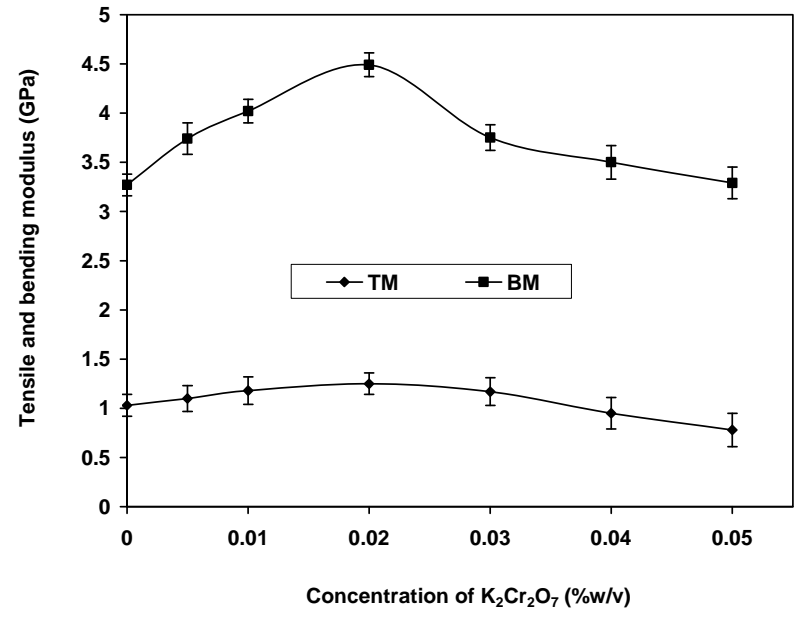

Figure 5. Effect of potassium dichromate on tensile and bending modulus of the composite.

$\mathrm{TM}$ and $\mathrm{BM}$ increase to $21.36 \%$ (from 1.03 to $1.25 \mathrm{GPa}$ ) and $37.31 \%$ (from 3.27 to $4.49 \mathrm{GPa}$ ) respectively from that of the control composite. The effect of $\mathrm{K}_{2} \mathrm{Cr}_{2} \mathrm{O}_{7}$ on impact strength (IS) of the composites is presented in Figure 6. The value of IS moves from $19.10 \mathrm{~kJ} / \mathrm{m}^{2}$ (for control composite) to $23.5 \mathrm{~kJ} / \mathrm{m}^{2}\left(0.02 \% \mathrm{~K}_{2} \mathrm{Cr}_{2} \mathrm{O}_{7}\right.$ treated composite). This value indicates $23.04 \%$ improvement over the IS value of the control sample. Elongation at break of the treated sample is depicted in Figure 7. It is observed that with the increase in concentrations of $\mathrm{K}_{2} \mathrm{Cr}_{2} \mathrm{O}_{7}$ solution, $\mathrm{Eb}$ decreases gradually. At $0.005 \%$ and $0.05 \% \mathrm{~K}_{2} \mathrm{Cr}_{2} \mathrm{O}_{7}$ treatment $\mathrm{Eb}$ had the values of $9.45 \%$ and $6.1 \%$ respectively. The values were $11.85 \%$ and $43.09 \%$ lower from that of the control sample. The finding of this observation reveals that composite based

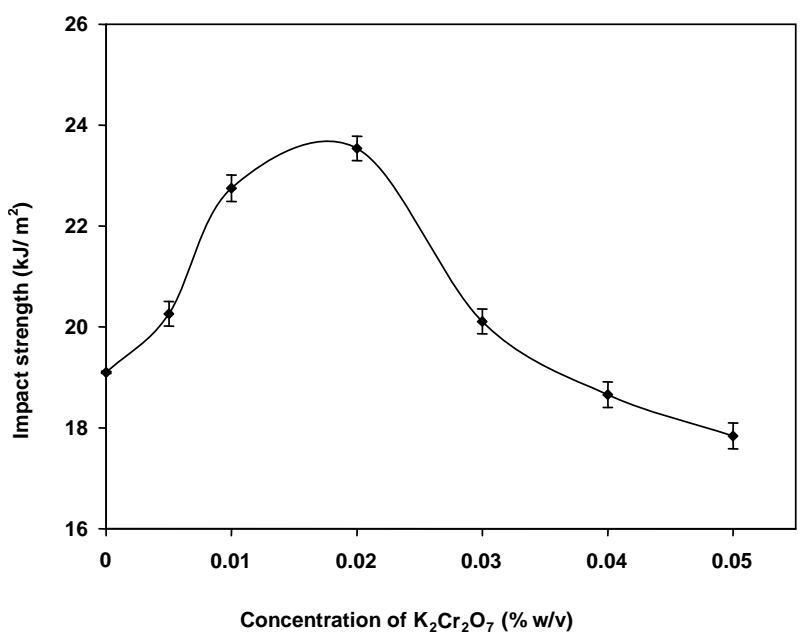

Figure 6. Effect of potassium dichromate on impact strength of the composite. 


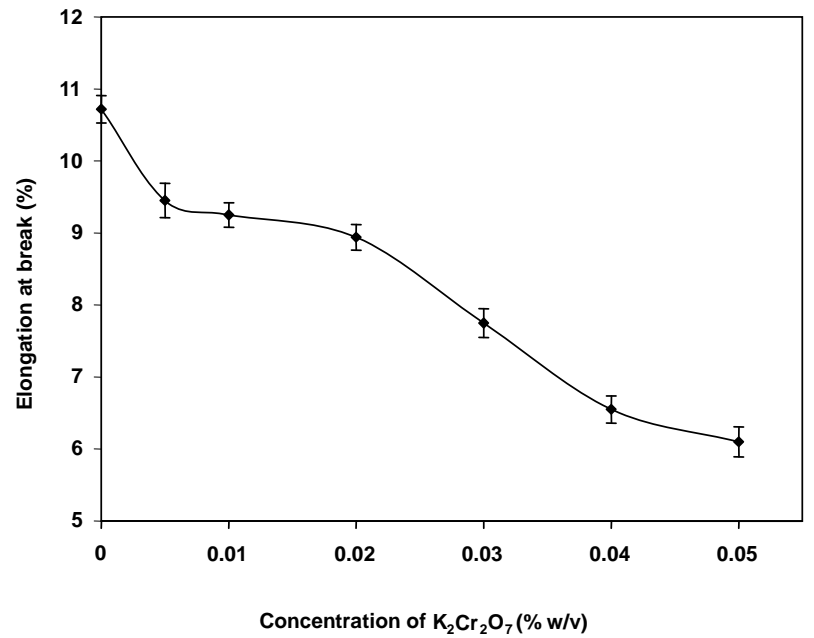

Figure 7. Effect of potassium dichromate on elongation at break of the composite.

on $0.02 \% \mathrm{~K}_{2} \mathrm{Cr}_{2} \mathrm{O}_{7}$ treated jute fabrics earns the highest values of all the mechanical parameters over the other combinations and also than that of the control composite.

The changes in mechanical properties of the composites upon treatment of jute fabrics with $\mathrm{K}_{2} \mathrm{Cr}_{2} \mathrm{O}_{7}$ may be explained on the basis of oxidizing effect of $\mathrm{K}_{2} \mathrm{Cr}_{2} \mathrm{O}_{7}$ on the cellulose materials. Jute fabrics may undergo chemical as well as physical changes upon the action of aqueous $\mathrm{K}_{2} \mathrm{Cr}_{2} \mathrm{O}_{7}$ solution. Depending on the strength of the oxidizing agent, jute fabrics may experience surface roughness and brittleness in fibers. At lower concentrations of $\mathrm{K}_{2} \mathrm{Cr}_{2} \mathrm{O}_{7}$ solution (up to $0.02 \%$ ), the oxidized jute fabrics may experience surface roughness and a reduction in compactness of the fiber bundles, which enhance effective surface area available for contact with the matrix. The additional sites of mechanical interlocking promote more interpenetration between the fibers and PP matrix. This might have caused improvement in the mechanical properties of the treated composites. At higher concentrations (such as $0.05 \%$ ), $\mathrm{K}_{2} \mathrm{Cr}_{2} \mathrm{O}_{7}$ may penetrate and attack into the amorphous regions of cellulose and surfaces of the crystallites that may degrade the fiberous materials [14]. This morphological change might have caused agglomeration of fibers in the matrix or inhomogeneous stress transfer when load is applied. As a result, jute fabrics treated with higher concentrated solution of $\mathrm{K}_{2} \mathrm{Cr}_{2} \mathrm{O}_{7}$ impart poor performance in the mechanical properties of the composite.

\subsection{Thermal Properties of PP, Treated and Untreated Jute Fabrics}

Thermogravimetric/Differential thermogravimetric (TG/ DTG) and differential thermal analyses (DTA) were performed to study the thermal properties of PP and jute fabrics (untreated and treated). Thermal investigations were carried out only for $0.02 \% \mathrm{~K}_{2} \mathrm{Cr}_{2} \mathrm{O}_{7}$ treated jute fabric since composite based on $0.02 \% \mathrm{~K}_{2} \mathrm{Cr}_{2} \mathrm{O}_{7}$ treated jute fabrics had the best mechanical properties over the other combinations. Figure 8 shows the different thermograms of PP. From DTG thermogram it is observed that a broad single peak starts around $371.6^{\circ} \mathrm{C}$ with a maximum degradation at $413.8^{\circ} \mathrm{C}$ at the rate of 1.634 $\mathrm{mg} / \mathrm{min}$. This peak corresponds to the rupture of $\mathrm{C}-\mathrm{C}$ chain bonds along with $\mathrm{H}-$ abstraction at the site of rupture $[16,18]$. PP is strongly hydrophobic (moisture absorption is $0 \%$ ) in nature and completely depleted at $426.8^{\circ} \mathrm{C}$ without formation of any char residue (TG thermogram). The endothermic peak at $163.9^{\circ} \mathrm{C}$ in DTA thermogram is related to the melting temperature of PP.

The thermograms of jute fabrics (untreated and treated) are depicted in Figure 9. DTG thermograms show that decomposition of fabrics occurs as a three step process. The first step process below $100^{\circ} \mathrm{C}$ corresponds to the loss of adsorbed water from the fabrics. The decomposition of hemicellulose of untreated and treated jute fabrics may occur at $296^{\circ} \mathrm{C}$ and $301.2^{\circ} \mathrm{C}$ with the rate of 0.390 and $0.152 \mathrm{mg} / \mathrm{min}$ respectively in the second process [16]. Weight loss at this stage is about 6 and $8 \%$ respectively. The strong third peak observed at $365.0^{\circ} \mathrm{C}$ (rate $1.781 \mathrm{mg} / \mathrm{min}$ ) and $363.0^{\circ} \mathrm{C}$ (rate $0.796 \mathrm{mg} / \mathrm{min}$ ) for untreated and treated jute fabrics respectively may be attributed to the decomposition of $\alpha$-cellulose [16]. The temperatures at $365.0^{\circ} \mathrm{C}$ and $363.0^{\circ} \mathrm{C}$ correspond to the weight loss of about 60 and $66.2 \%$ respectively. It is also mentionable that like the previous report [16], no decomposition of lignin is observed here although, lignin comprises around $13 \%$ of the jute fiber weight. Untreated and treated jute fabrics produce 20.7 and $9.1 \%$ residues

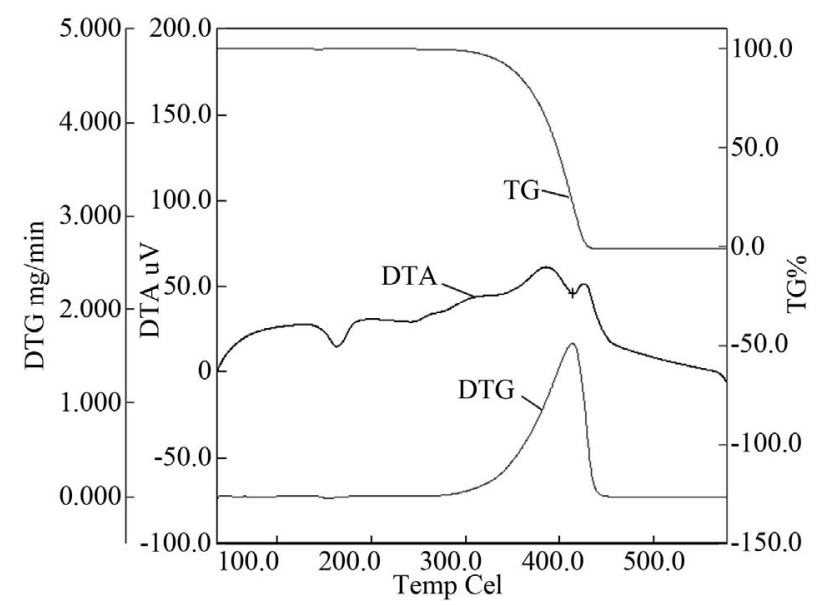

Figure 8. Thermograms of PP. 


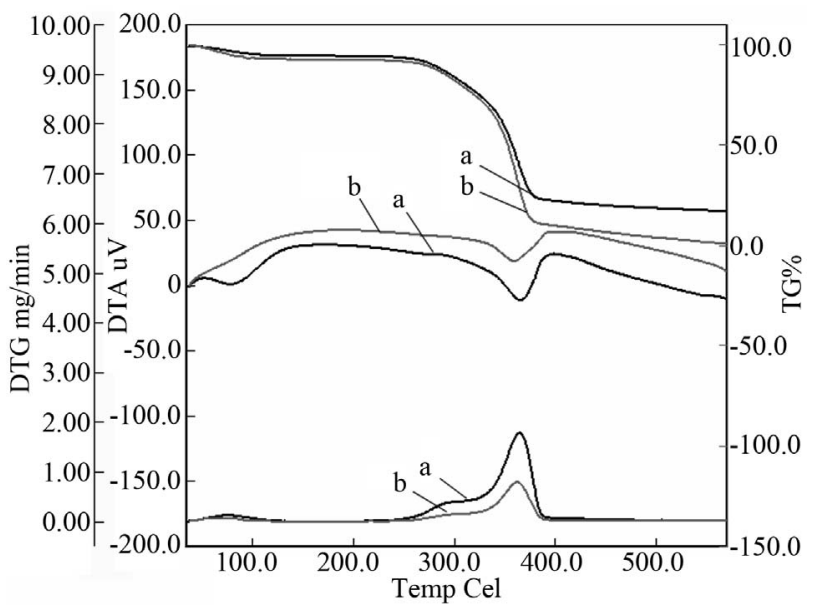

Figure 9. Thermograms of (a) untreated jute fabric and (b) $0.02 \%$ potassium dichromate treated jute fabric. (Upper part-TG, middle part-DTA and bottom part-DTG thermogram).

at $377.8^{\circ} \mathrm{C}$ and $374.9^{\circ} \mathrm{C}$ respectively (TG thermogram). The formation of char residues may involve initial physical desorption of water, intramolecular dehydration, formation of carboxyl and carbon-carbon double bonds, cleavage of glycosidic linkage and rupture of $\mathrm{C}-\mathrm{O}$ and $\mathrm{C}-\mathrm{C}$ bonds and condensation and aromatization of carbon atoms from each original pyranose ring to form discrete graphite layers $[16,19,20]$. The investigation explores that jute fabrics are less thermally stable compared to PP in nitrogen environment. The similar observation was also reported in the previous literature $[16,19]$. It is also observed that treatment of jute fabrics with $\mathrm{K}_{2} \mathrm{Cr}_{2} \mathrm{O}_{7}$ does not affect the thermal stability of jute fabrics remarkably.

\subsection{Effect of $\mathrm{K}_{2} \mathrm{Cr}_{2} \mathrm{O}_{7}$ on Thermal Properties of Composites}

Composite based on $0.02 \% \mathrm{~K}_{2} \mathrm{Cr}_{2} \mathrm{O}_{7}$ treated jute fabrics had the best mechanical properties over the other combinations, so thermal investigations were carried out only for this treated composite. The thermograms of untreated and treated composites are presented in Figure 10. TG thermograms show that loss of adsorbed water for untreated and treated composites is 1.9 and $2.0 \%$ respectively. It is thought that during processing or testing, water could have been absorbed from the atmosphere if the fibers were not fully wetted by the matrix in the composite [21]. The residues obtained for untreated and treated composites are 9.4 and $10.1 \%$ at $438.6^{\circ} \mathrm{C}$ and $463.2^{\circ} \mathrm{C}$ respectively (TG thermograms). The formation of char residues has been discussed earlier. In composites, two stage degradations occur: first stage is responsible for jute fabric and second stage is for PP. The DTG thermograms

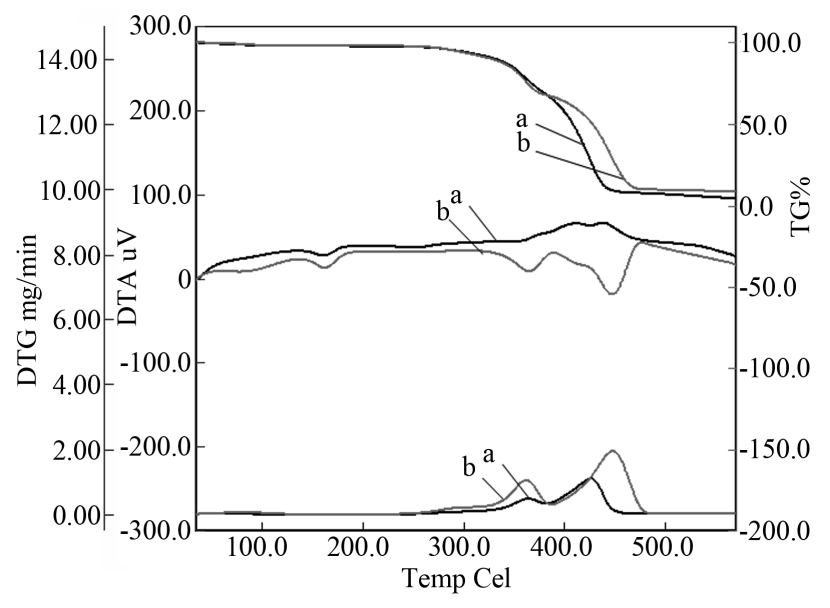

Figure 10. Thermograms of (a) control and (b) $0.02 \%$ potassium dichromate treated jute fabrics -PP composites. (Upper part-TG, middle part-DTA and bottom part-DTG thermogram).

show that maximum degradation temperatures of untreated composite for first and second stage are $365.1^{\circ} \mathrm{C}$ and $426.7^{\circ} \mathrm{C}$ respectively and those for treated composite are $363.9{ }^{\circ} \mathrm{C}$ and $448.0^{\circ} \mathrm{C}$. From these findings it can be realized that maximum degradation temperature of untreated $\left(365.0^{\circ} \mathrm{C}\right)$ and treated $\left(363.0^{\circ} \mathrm{C}\right)$ jute fabrics remains almost unchanged in the composites. At second stage, the maximum degradation temperature of neat PP $\left(413.8^{\circ} \mathrm{C}\right)$ is shifted to higher temperature regions by $12.9^{\circ} \mathrm{C}$ and $34.2^{\circ} \mathrm{C}$ for untreated $\left(426.7^{\circ} \mathrm{C}\right)$ and treated $\left(448.0^{\circ} \mathrm{C}\right)$ composites respectively. It indicates that treatment of jute fabrics with $0.02 \% \mathrm{~K}_{2} \mathrm{Cr}_{2} \mathrm{O}_{7}$ improves the thermal stability of the composite to a large extent which justifies the development of strong fiber-matrix interface in treated composite.

\subsection{Interfacial Properties of the Composites}

To find out the fiber matrix adhesion inside the composites, SEM studies were carried out. SEM images of the tensile fractured surfaces of the untreated (a) And 0.02\% $\mathrm{K}_{2} \mathrm{Cr}_{2} \mathrm{O}_{7}$ treated (b) Jute fabrics reinforced PP composites are presented in Figure 11. This is clearly indicated for untreated composites that fiber pull-out is quite higher and the bonding between jute and matrix is not good. Small gaps are evident in the matrix near to the jute fibers. However, for treated composite interface suggested better fiber matrix adhesion which is supported by low fiber pull-out. From this investigation this is clearly evidenced that fiber matrix interfacial adhesion is better for treated composite compared to that for the untreated one. The data presented above for the mechanical properties of both types of composites, also supported the SEM observation. 


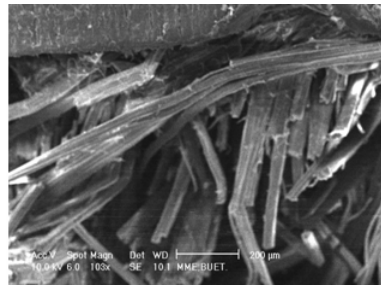

(a)

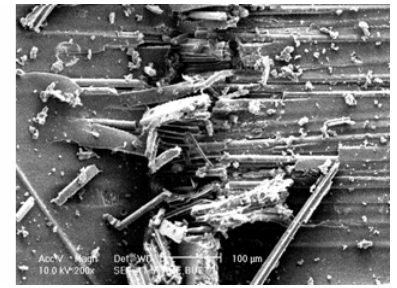

(b)
Figure 11. Scanning electron microscopic images of the tensile fractured surfaces of (a) control and (b) $0.02 \%$ potassium dichromate treated jute fabrics reinforced PP composites.

\subsection{Water Uptake of the Composites}

Jute fiber is hydrophilic in nature due to presence of polar group (-OH group) in its structure. The polar group forms hydrogen bond by absorbing water molecules and this induces swelling in fibers. Composites in this study contain about $45 \%$ jute fibers (by weight). Water may penetrate into the composite through the cutting edges. The percent water uptake of control and $\mathrm{K}_{2} \mathrm{Cr}_{2} \mathrm{O}_{7}(0.02 \%)$ treated jute-PP composites was measured with different time intervals (days) and is presented in Figure 12. It is observed that water absorption of control composite is higher than that of the treated composites. The percent water gain of the control composite is $8.0-13 \%$ during the experimental periods which is dropped down to 7-10 $\%$ for treated composite. In treated composite better fiber-matrix adhesion might be responsible for the lower tendency of water uptake as compared to control composite. It is also noticed that during the period of $24 \mathrm{hr}$,

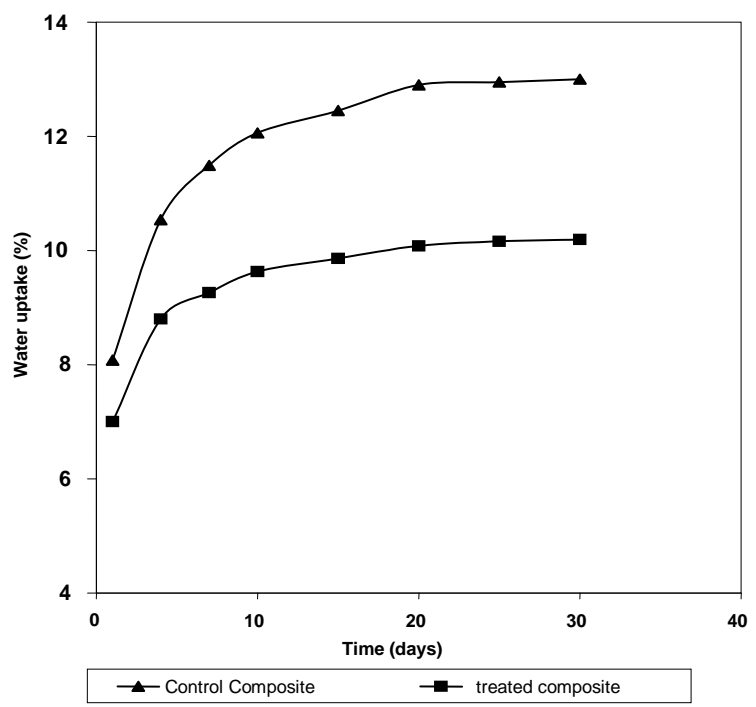

Figure 12. Percent water uptake of control and potassium dichromate treated jute fabrics -PP composites. water absorption for both the composites is very rapid. After 15 days of water soaking, percent water gain of control composite remains almost static. This phenomenon is observed for treated composite after 7 days of soaking periods. At static conditions, fibers get saturated with water molecules and can no more gain water molecules from the surroundings.

\section{Conclusions}

The mechanical and thermal behavior of jute fabric/PP composites was studied with special reference to fiber content and fiber treatment. The mechanical properties of the untreated composites were found highest at $45 \%$ fiber content. Treatment of jute fiber in polypropylene matrix brought an important change in the properties of the composites. Composites (45\% fiber content) prepared with $0.005-0.03 \% \mathrm{w} / \mathrm{v} \mathrm{K}_{2} \mathrm{Cr}_{2} \mathrm{O}_{7}$ (in aqueous medium) treated jute fabrics showed better performance than that of the control composite. It was found that $0.02 \%$ $\mathrm{K}_{2} \mathrm{Cr}_{2} \mathrm{O}_{7}$ treated composite produced the highest values of all mechanical properties over the other combinations. Thermal analytical data showed that thermal stability of the composites either treated or untreated was higher than that of neat PP or jute fabrics. $\mathrm{K}_{2} \mathrm{Cr}_{2} \mathrm{O}_{7}$ treatment improves the thermal stability of the composite considerably. Scanning electron microscopic analysis of the control and treated composites supported that some changes happened due to the $\mathrm{K}_{2} \mathrm{Cr}_{2} \mathrm{O}_{7}$ treatment. Fractured surfaces of the treated composite showed low fiber pull-out and thus indicated better fiber matrix adhesion over the untreated composite interface. The tendency of water uptake of the composite was also reduced due to $\mathrm{K}_{2} \mathrm{Cr}_{2} \mathrm{O}_{7}$ treatment.

\section{REFERENCES}

[1] G. Bogoeva-Gaceva, M. Avella, M. Malinconico, A. Buzarovska, A. Grozdanov, G. Gentile, and M. E. Errico, "Natural Fiber Eco-Composites," Polymer Composites, Vol. 28, 2007, pp. 98-107.

[2] M. M. Hassan, M. R. Islam, S. Shehrzade and M. A. Khan, "Influence of Mercerization along with Ultraviolet (UV) and Gamma Radiation on Physical and Mechanical Properties of Jute Yarn by Grafting with 3-(Trimethoxysilyl) Propylmethacrylate (Silane) and Acrylamide Under UV Radiation," Journal of Polymer Plastics Technology and Engineering, Vol. 42, 2003, pp. 515-531.

[3] M. A. Khan, K. M. I. Ali, C. Koppe and G. Hinrichsen, "Study of Tensile Properties of Biopol-Jute Composites," Journal of Polymer Plastics Technology and Engineering, Vol. 38, No.1, 1999, p. 99.

[4] B. N. Dash, A. K. Rana, H. K. Mishra, S. K. Nayak, S. C. Misra and S. S. Tripathy, "Novel Low-Cost Jute-Polyester Composite Part 1, Processing, Mechanical Properties and 
SEM Analysis," Polymer Composites, Vol. 20, No. 1, 1999, p. 62.

[5] K. Joseph, S. Thomas and C. Pavithran, "Effect of Chemical Treatment on the Tensile Properties of Short Sisal Fiber-Reinforced Polyethylene Composites," Polymer, Vol. 37, No. 23, 1996, pp. 5139-5149.

[6] K. Joseph, S. Thomas and C. Pavithran, "Dynamic Mechanical Properties of Short Sisal Fiber Reinforced Low Density Polyethylene Composites," Journal of Reinforced Plastic and Composites, Vol.12, No. 2, 1993, pp. 139-155.

[7] S. S. Tripathy, G. Levita and L. D. Landro, "Interfacial Adhesion in Jute-Polyolefin Composites," Journal Polymer Composites, Vol. 22, No. 6, 2001, pp. 815-822.

[8] A. K. Mohanty, L. T. Drzal and M. Misra, "Engineered Natural Fiber Reinforced Polypropylene Composites: Influence of Surface Modifications and Novel Powder Impregnation Processing," Journal of Adhesion Science and Technology, Vol. 16, 2002, p. 999.

[9] A. L. Leão, J. C. Caraschi and I. H. Tan, "Curaua Fiber-A Tropical Natural Fibers from Amazon Potential and Applications in Composites," In: E. Frollini, A. L Leão and L. H. C. Mattoso, Eds., Natural Polymers and Agrofibers Composites, Brazil, 2000, pp. 257-272.

[10] L. Xue, L. G. Tabil and S. Panigrahi, "Chemical Treatments of Natural Fibers for Use in Natural Fiber-Reinforced Composites. A Review" Journal of Polymer and the Environment, Vol. 15, No. 1, 2007, pp. 25-33.

[11] P. J. Kangle and G. M. Nabar, "Studies in Chemically Modified Celluloses. I. Oxidative Susceptibility of Chemically Modified Cellulose," Journal of Applied Polymer Science, Vol. 13, No. 2, 2003, pp. 323-336.

[12] V. A. Shenai and A. G. Date, "Studies in Chemically Modified Celluloses IX. Oxidation of Cellulose in the Presence of Chelating Agents," Journal of Applied Polymer Science, Vol. 20, No. 2, 2003, pp. 385-391.

[13] A. Hebeish, A. Z. Moursi, A. Waly and M. H. El-Rafie, "Dyeing of Chemically Modified Cellulose. IV. Dyeing of Oxidized Celluloses with Some Reactive and Direct Dyes," Journal of Applied Polymer Science, Vol. 24, No. 2, 2003, pp. 385-394.

[14] T. P. Nevell, "Oxidation," In: R. L. Whistler Ed., Methods in Carbohydrate Chemistry, Vol. III, Academic press, New York, 1963, pp. 164-184.

[15] T. T. L. Doan, H. Brodowsky and E. Mäder, "Jute Fiber/Polypropylene Composites II. Thermal, Hydrothermal and Dynamic Mechanical Behaviour," Composites Science and Technology, Vol. 67, No. 13, 2007, pp. 2707-2714.

[16] P. V. Joseph, K. Joseph, S. Thomas, C. K. S Pillai, V. S. Prasad, G. Groeninckx and M. Sarkissova, "The Thermal and Crystallization Studies of Short Sisal Fiber Reinforced Polypropylene Composite," Composite: Part A, Vol. 34, No. 3, 2003, pp. 253-266.

[17] S. Mohanty and S. K. Nayak, "Interfacial, Dynamic Mechanical, and Thermal Fiber Reinforced Behavior of MAPE Treated Sisal Fiber Reinforced HDPE Composites," Journal of Applied Polymer Science, Vol. 102, 2006 , pp. 3306-3315.

[18] J. R. Daniel, "Encylopedia of Polymer Science and Engineering," 2nd Edition, John Wiley, New York, 1985.

[19] M. Idicula and S. Thomas, "Effect of Fibre Loading and Fibre Ratio on the Mechanical Properties of Intimately Mixed Banana/Sisal Hybrid Fibre Reinforced Composites," 5th Global Wood and Natural Fibre Composites Symposium, Kassel, Germany, 2004, pp. 27-28.

[20] F. Mengeloglu and K. Karakus, "Some Properties of Eucalyptus Wood Flour Filled Recycled High Density Polyethylene (HDPE) Polymer-Composites," Turkish Journal of Agriculture and Forestry, Vol. 32, 2008, pp. $1-10$.

[21] S. H. Aziz and M. P. Ansell, "The Effect of Alkalization and Fiber Alignment on the Mechanical and Thermal Properties of Kenaf and Hemp Bast Fibre Composites: Part 2-Cashew Nut Shell Liquid Matrix," Composites Science and Technology, Vol. 64, 2004, pp. 1231-1238. 